\title{
LETTER FROM THE EXECUTIVE DIRECTOR
}

As many of you already are aware, on January 30, the African Studies Association launched a major overhaul to improve our website and our online system. The Secretariat has been working assiduously to streamline the process for accessing the new and enhanced features of myASA, which integrates membership features, including an enhanced members-only, searchable ASA Directory; voting; the Annual Meeting Call for Proposals submission system; an enhanced shopping cart that now makes publications available for purchase online and that accepts an expanded range of credit cards, including from foreign banks, which makes it easier for international members to process payments; and communities, which will allow individuals and groups to disseminate announcements, news, and other important correspondence that can be archived in a dedicated file library for future reference. We are also working to make the website an even greater resource not only for individuals, but also for the Association's 34 coordinate organizations, which now have a clearly designated link on the ASA website. Please take a moment to update your myASA profile; the search for colleagues in the Member Director is far more rewarding if contact and demographic information (i.e., discipline, countries of interest, availability as an asylum/media expert, interest in service on an ASA committee, etc.) is current.

As with all new technology, an initial period of familiarization and the inevitable glitches are to be expected. While many of you accessed the website smoothly, others shared the experience of ambiguities that they encountered, which has enabled the Secretariat to work quickly with the software vendors to make adjustments, to the benefit of future users. One result was that the Call for Proposals for this year's Annual Meeting ("Africa at a Crossroads," November 19-22 in New Orleans, LA), was extended to March 31. All attempts to submit a proposal or to volunteer to serve as a chair or as a discussant, as evidenced by written or voice mail contact with the Secretariat on or before the March 31 deadline, will be processed for review by the Program Committee. The preliminary program, which will contain the proposals that were accepted for presentation by the Program Committee, chaired by Aili Tripp (University of Wisconsin-Madison), will be available on the ASA website in July. In the meantime, the Local Arrangements Committee, co-chaired by Romanus Ejiaga (Southern University-New Orleans), James P. Mokhiber (University of New Orleans), and Steven Salm (Xavier University of Louisiana) is hard at work to ensure a wonderful welcome.

The 2009 election period opened earlier this year, on March 3rd. Although a technical display error led us to close the elections and re-open a new ballot on March 23, the J une 5 deadline still will enable next year's Nominating Committee to have the results of ballot in time to better ensure diversity and balance on the member-elected Board of Directors, whose volunteer leadership is so critical to advancing the Association's mission.

While much has been accomplished to streamline processes, add more explanatory text at strategic points, and augment the FAQ, the Secretariat welcomes new suggestions that undoubtedly will surface, particularly as users become more comfortable with navigating the site. The primary goal is to ensure that the website is as user-friendly as possible for professional development and networking. Together, we will explore the website's many new features and transform it into a powerful tool for promoting African studies.

Investing in technology is one way to invest in the future. We know the economic downturn is affecting everyone, but we also know that professional services are highly valued. We are convinced that your investment in membership in the ASA, that your participation in the ASA Annual Meeting, and that your contributions to the ASA endowment will be key to our shared success in bringing together people with a scholarly and professional interest in Africa. 